BULLETIN Bulletin hispanique

HispaniquE Université Michel de Montaigne Bordeaux

114-1 | 2012

Varia

\title{
Los libreros Ángel Corradi y Antoine Boudet
}

y la importación de libros franceses para la Academia de San Fernando

\section{Gabriel Sánchez Espinosa}

\section{(2) OpenEdition}

Journals

Edición electrónica

URL: http://journals.openedition.org/bulletinhispanique/1833

DOI: 10.4000/bulletinhispanique.1833

ISSN: 1775-3821

Editor

Presses universitaires de Bordeaux

\section{Edición impresa}

Fecha de publicación: 1 junio 2012

Paginación: 195-216

ISBN: 978-2-86781-812-7

ISSN: 0007-4640

Referencia electrónica

Gabriel Sánchez Espinosa, "Los libreros Ángel Corradi y Antoine Boudet », Bulletin hispanique [En línea], 114-1 | 2012, Publicado el 01 junio 2015, consultado el 30 abril 2019. URL : http://

journals.openedition.org/bulletinhispanique/1833; DOI : 10.4000/bulletinhispanique.1833 


\title{
Los libreros Ángel Corradi y Antoine Boudet, y la importación de libros franceses para la Academia de San Fernando
}

\author{
Gabriel SÁNChez Espinosa \\ Queen's University Belfast - Northern Ireland
}

Sous les règnes de Ferdinand VI et Charles III, le libraire génois Angel Corradi faisait partie de l'élite commerciale du marché du livre de Madrid. Cet article présente sa biographie et décrit sa librairie et son activité en tant qu'importateur de livres français et d'instruments mathématiques pour l'Académie Royale de San Fernando en association avec le libraireimprimeur Antoine Boudet, son principal correspondant à Paris.

El genovés Ángel Corradi perteneció a la élite del comercio librero del Madrid de Fernando VI y Carlos III. Este estudio perfila su biografía, ofrece algunos datos en cuanto a las características físicas de su librería y estudia su actividad como importador de libros e instrumentos matemáticos para la Real Academia de San Fernando, en la que se sirvió del impresor-librero parisino Antoine Boudet, su principal corresponsal en París.

The Genoese bookseller Angel Corradi belonged to the elite of the commercial book market in Madrid, during the reigns of Ferdinand VI and Charles III. This article presents Corradi's biography, describes his bookshop and his activity as an importer of French books and mathematical instruments for the Royal Academy of San Fernando, in association with the printer-bookseller Antoine Boudet, his main correspondent in Paris.

Mots-clés : Ángel Corradi, Antoine Boudet, libraire, librairie, Académie, importation, instruments mathématiques, Globes.

$\mathrm{E}$ L 18 de enero de 1746, la Gaceta de Madrid, anunciaba la venta de un libro nuevo titulado Actos Christianos para conseguir la verdadera felicidad, obra del historiador franciscano Nicolás de Jesús Belando, que «se hallarà en la Libreria Italiana de Angel Corradi, calle de las Carretas» ${ }^{1}$. Se trata de

1. Gaceta de Madrid -a partir de aquí GM-, 18 de enero de 1746, p. 24. Este trabajo es una primera entrega de un extenso estudio sobre la figura de Ángel Corradi que se incluirá en un libro dedicado a los libreros madrileńos de la segunda mitad del siglo XVIII, fruto del proyecto 
la primera mención conocida del librero Ángel Corradi, que por entonces se hizo cargo del negocio de su tío materno Giacomo Filippo Repetto, con librería abierta en Madrid desde 1725 o 1726, años en que, según rememora fray Martín Sarmiento en 1743, impulsado un tanto el comercio literario por el establecimiento de la Biblioteca Real y la fundación de la Academia Espańola, y "comenzando ya á descubrirse compradores de libros curiosos, no faltaron libreros extrangeros que viniesen á establecerse en Madrid», como fue el caso de los franceses Barthélemy y Simond, y los italianos Repetto y Antonio Baroni, "y derramando asi estos como los Franceses diferentes vendedores de sus libros por España, comenzó á extenderse algo la venta y compra de libros, y los libreros nuestros nacionales comenzaron á traer el surtimiento de los que habian de vender en derechura de los paises extrangeros ${ }^{2}$.

La dinastía Repetto-Corradi de mercaderes de libros la inició el negociante de libros genovés Giovanni Battista Repetto, inscrito en el gremio de librerosencuadernadores de dicha ciudad-estado portuaria, eminentemente mercantil, a comienzos de febrero de 1702 y escogido consejero del mismo en 1729 , quien, manteniendo un pequeño establecimiento en Génova, tejió una red de contactos comerciales en las mayores ciudades italianas, tenía tienda abierta en Nápoles ya en 1713, y exportaba libros a Espańa a través del puerto de Alicante a mediados de los años veinte. Tuvo cuatro hijos, de los cuales le sobrevivieron tres: Giacomo Filippo, nacido hacia 1689, y dos hijas, una de ellas Teresa, madre de Angelo Corradi. Activo todavía durante la década de los treinta, el patriarca Giovanni Battista Repetto debió fallecer con anterioridad a 1744, dejando en su testamento dos tercios de sus propiedades a su hijo Giacomo Filippo Repetto, y el tercio restante a sus dos hijas.

Giacomo Filippo Repetto, inscrito en el gremio de libreros-encuadernadores genovés en 1714, volcó su atención más hacia el negocio de exportación que a la actividad del establecimiento radicado en Génova. En 1721 residía en Nápoles, encargado de vigilar los negocios familiares con los libreros Giovanni Altobello y Lorenzo Torino, al que se le habían hecho envíos por valor de dos mil ducados. Además de en Nápoles, negoció en Venecia, Roma, Milán, Bolonia, Luca y, a través de Marsella, exportaba libros venecianos a la Península Ibérica. Por lo que respecta a Madrid, los últimos anuncios de obras a la venta en su librería italiana de la calle de las Carretas, corresponden al año $1744^{3}$. Gregorio Mayans, que frecuentó la librería de Repetto durante sus años de bibliotecario real, y su íntimo Manuel Martínez Pingarrón, su principal intermediario en Madrid para la adquisición de libros, continúan haciendo referencia a dicha librería en su correspondencia, según costumbre, como "casa de Repeto» hasta finales de 1747. Repetto debió traspasar el negocio a su sobrino Ángel

Towards a catalogue of Madrid bookshops, 1759-1814, financiado por el programa conjunto entre la British Academy y el CSIC. Me gustaría dedicar este artículo a Nigel Glendinning, que despertó mi interés sobre este interesante personaje.

2. Vid. M. Sarmiento, «Reflexiones literarias para una Biblioteca Real...», Semanario Erudito, XXI, 1789, p. 131-132. El benedictino Sarmiento residía en la Corte desde 1710.

3. GM, 24 de marzo, y 11 y 18 de agosto de 1744 . 
Corradi entre 1744 y 1746, pasando a residir en Génova. Curiosamente, en un anuncio de la Gaceta correspondiente a agosto de 1746 se produce el lapsus de denominar su librería de la calle de las Carretas, como de "Angel Repeto", lo que parece indicar que la transición en la propiedad del negocio era todavía un hecho reciente, que no había logrado contrarrestar el hábito ${ }^{4}$. El 29 de julio de 1749, Giacomo Filippo Repetto falleció repentinamente en Aviñón, uno de los principales centros de exportación de libros en latín con destino al mercado ibérico, a donde se había dirigido para seguir sus tratos con el librero-impresor Alexandre Giraud 5 .

Ángel Corradi nació en Génova hacia 1709. Sus padres, vecinos de dicha ciudad-estado, se llamaban don Giovanni Battista Corradi y doña Teresa Repetto, y vivían todavía en agosto de 1747. El 9 de febrero de 1719, cuando sólo tenía diez años de edad, le acogió como aprendiz su abuelo Giovanni Battista Repetto, pasando posteriormente al servicio de su tío Giacomo Filippo. Con anterioridad al 15 de agosto de 1747, Corradi había contraído matrimonio con Teresa Polonia Musante, nacida en el lugar de San Pietro di Quinto, en las afueras de Génova, hija de don Miguel Musante, vecino de dicha villa, y dońa Nicolasa Ravina, ya por entonces difunta. Teresa Musante llevó a su matrimonio una dote de trece mil reales. La nada despreciable herencia de Giovanni Battista Repetto -en Génova poseía la suma de veintidós mil liras en líquido, entre depósitos en el Banco di San Giorgio y lisbonine de oro, a lo que había que sumar los préstamos que había efectuado tanto en Génova como en el exterior-, provocó el conflicto entre sus herederos entre septiembre de 1749 y marzo de 1751, con episodios como el secuestro de los bienes del difunto en Venecia y Roma. Finalmente, la herencia del tío Repetto, valorada en ochenta mil liras, suma que incluía el dinero líquido, los créditos otorgados y el valor de la librería genovesa, se adjudicó a su hermana Teresa y a los tres hijos de ésta: Angelo, Bartolomeo y Giambattista Corradi, recibiendo cada uno de éstos unas veinte mil liras. Angelo o Ángel declaró haber heredado de su tío la suma de quince mil pesos sencillos -es decir, la importante suma de 225.000 reales de vellón ${ }^{6}$. Los Corradi tuvieron una sola hija, María Inés Corradi, natural de Madrid, que en 14 de julio de 1778 tenía veinticinco años,

\footnotetext{
4. "Libro nuevo: idèa de una nueva Historia General de la America Septentrional, fundada sobre material copioso de Figuras, Symbolos, Caractères, y Geroglificos; Cantares, y Manuscritos de Autores Indios, ultimamente descubiertos, su Autor el Cavallero Lorenzo Boturini Benaduci, Señor de la Torre, y de Hono; se hallarà en la Librería de Angel Repeto, calle de las Carretas.» (GM, 16 de agosto de 1746, p. 264).

5. Los datos biográficos sobre Giovanni Battista y Giacomo Filippo Repetto se han tomado de los artículos de A. Petrucciani, «Il libro a Genova nel Settecento. II.1. La libreria genovese: composizione, andamento, caratteristiche», La bibliofilia, 96.2, 1994, p. 151-193 y «ll libro a Genova nel Settecento. II.2. I librai genovesi (1685-1797)», La bibliofilia, 96.3, 1994, p. $227-$ 278 , a cuyas indicaciones estoy sumamente agradecido.

6. Véase el poder para testar con fecha 15 de agosto de 1747, ante el escribano Eugenio Portales, incluso dentro del testamento de don Ángel Corradi, mercader de libros que fue en esta Corte, otorgado por dońa Teresa Musante en 14 de julio de 1778, ante el escribano de provincia Francisco Antonio de Sobrevilla (AHPM, tomo 21142, fol. 182-189).
} 
por lo que debió nacer en 1752-53, y era de estado viuda, habiendo contraído matrimonio en Madrid a finales de 1773, a sus diecinueve o veinte ańos, con el pintor veneciano Lorenzo Tiepolo ${ }^{7}$, de treinta y siete años, que falleció dos años y medio después, el 2 de mayo de 1776. A su matrimonio, María Inés Corradi aportó en dinero efectivo, vestidos, alhajas y otros efectos la cantidad de diez mil pesos -150.000 reales-, a cuenta de la legítima paterna. Ángel Corradi falleció en Madrid el 10 de febrero de 1777, recibiendo sepultura en la bóveda de los capellanes de la parroquia de Santa Cruz.

La librería de Ángel Corradi estaba situada en el n ${ }^{\circ} 4$ de la calle Carretas, correspondiente a la manzana 208 de la Planimetría general, calle que con la división de Madrid en cuarteles y barrios del año 1768, resultó incluida en el cuartel de la Plaza Mayor, barrio de Santa Cruz, en un edificio con accesorias a la calle ancha de Majaderitos, la actual calle Barcelona ${ }^{8}$.

Carretas, que nace de una Puerta del Sol constituida en el siglo XVIII en el espacio público que atrae, concentra e irradia el comercio más dinámico de la capital, reunía junto con la franja de la calle Mayor correspondiente al convento agustino de San Felipe el Real, la mayor concentración de comercios de librería de la Corte, con la particularidad de que en Carretas se trataba principalmente de tiendas, mientras que en torno al foco de las gradas de San Felipe el Real interactuaban puestos y tiendas de libros ${ }^{9}$. El viajero angloitaliano Giuseppe Baretti, que visitó Madrid en 1760, la describe como «chiefly inhabited by printers and booksellers», añadiendo seguidamente que

Having looked into several of the many booksellers-shops that are in that street de las Carretas and in some other, I had reason to be astonished at the vast quantity of books the Spaniards have written in their language. Before I came here, I knew that they have in it a great deal of divinity, history, and poetry: yet I had scarcely any idea of their stock of literature. From the many titles of books that have passed in review under my eyes since I entered the

7. El famoso fresquista Giambattista Tiepolo había llegado a Madrid a comienzos de junio de 1762, en compañía de sus hijos y colaboradores Giandomenico y Lorenzo, para pintar los frescos del Palacio Nuevo. Como fresquista, Lorenzo llevó a cabo un gabinete chinesco en 1763 y la bóveda de los pájaros para el gabinete del infante don Luis, en 1764. Lorenzo se singularizó pronto en el panorama pictórico español por sus obras al pastel, llevando a cabo una serie de retratos de los infantes en 1763 y, tras la muerte de su padre el 27 de marzo de 1770, su serie de tipos populares madrileńos de los ańos 1771-73, continuada en un encargo del príncipe de Asturias de 1775. Para la obra al pastel de L. Tiepolo, véase el catálogo Lorenzo Tiepolo (Madrid, Museo del Prado, 1999), correspondiente a la exposición celebrada en dicho museo, y para lo todo lo relativo a sus sueldos, gastos e inversiones el estudio de J.-M. de la Mano, «Lorenzo Tiepolo, vida privada y oficio de un veneciano al servicio de Carlos III», en dicho catálogo, p. 78-95.

8. Dicho inmueble estuvo incluido en el mayorazgo fundado en octubre de 1661 por don Antonio Carnero. En 1766 disfrutaba este mayorazgo don Joaquín de Sobremonte Carnero y Zárate, conde de Villafranca de Gaitán, que falleció sin sucesión el 23 de junio de 1766. El mayorazgo recayó entonces en el marqués de San Antonio de Mira el Río, cuyo título y rentas correspondían al conde de Noblejas (Archivo Contaduría de Hipotecas de Madrid, leg. correspondiente a la Manzana 208).

9. Sobre dicho espacio comercial, véase mi artículo «Los puestos de libros en las gradas de San Felipe de Madrid en el siglo XVIII», en Goya, 335, 2011, p. 142-155. 
kingdom, I have now got a notion that we have too much neglected an acquaintance with the knowledge collected by scholars of this country. Of the learning of France we are tolerably informed in our capital cities, nor are we perfect strangers to that of England, as we have translated a pretty considerable number of English books. But we have shamefully overlooked the books of Spain, of late at least ${ }^{10}$.

El caserío de Carretas, dominado en el extremo de la Puerta del Sol por los pináculos del Hospital del Buen Suceso y la iglesia de la Victoria, y en el extremo de la Plaza del Ángel por los de la Trinidad Calzada, comenzaba su pendiente en la esquina de Sol con el lateral del sólido edificio de la nueva Casa de Correos y Postas, finalizado en 1768 según proyecto del arquitecto francés Jaime Marquet, una larga decena de años después de que el arquitecto Ventura Rodríguez derribase las casas particulares que ocupaban su solar en esa esquina de la manzana 206. Ya a finales de los cincuenta contaba la calle con uno de los primeros cafés de la Corte madrileña ${ }^{11}$.

Por lo que respecta al aspecto interior y exterior de la librería de Corradi, a falta de otros testimonios, los únicos datos a nuestra disposición son los que se deducen del inventario de sus bienes presentado por Antonio Bailo el 9 de febrero de 1781, al objeto de obtener una escritura de capital a la sazón de hacer público su matrimonio ${ }^{12}$. Bailo, con anterioridad a finales de junio de 1779, se había hecho con el local de la antigua librería de Corradi -no con sus libros-, cuyo traspaso se había propuesto en la Gaceta de Madrid de 18 de junio de ese año:

Se dá noticia al público que se traspasa la Librería de Corradi á fin que qualquiera que quisiere hacer postura acuda á la misma casa calle de las Carretas $\mathrm{N}^{\circ} 4^{13}$.

La tienda librería debía estar compuesta por una sala principal, cubierta en tres de sus lados por estantes (valorados en 820 reales), una trastienda, con estantes dados de color, claveteados y con su guardapolvo de tafetán (valorados en 600 reales), y una tercera pieza con un estante grande (valorado en 150 reales). Tenía dos mesas: una mesa grande con dos cajones y sus pies fuertes de media alfafia (tasada en 105 reales) y otra mesa más mediana (que se aprecia en 44 reales). Dichas mesas estaban vestidas con dos cubiertas de paño azul de tres varas y media de longitud -es decir, 2,92 metros- (valoradas en 90 reales), y servirían para exponer las novedades o las obras en proceso de publicación,

10. En G. Baretti, A journey from London to Genoa, through England, Portugal, Spain, and France..., London, 1770, 2 vols.; en carta LVII, vol. II, p. 6-7.

11. En la sección de pérdidas del Diario Noticioso Universal, correspondiente al miércoles 3 de septiembre de 1760, encontramos el siguiente anuncio: «La persona que huviere encontrado un juego de Evillas de piedras de Francia, que se perdieron desde el Café de la calle de las Carretas, hasta la Plazuela del Angel: acuda para la restitucion à dicha casa del Café, en donde darán las señas, y el hallazgo.» (p. 3)

12. Escritura de capital e inscripción de bienes otorgada por don Antonio Francisco Bailo y doña Teresa Musante, su mujer, vecinos de esta villa, ante el escribano de provincia Francisco Antonio de Sobrevilla (AHPM, tomo 21144, fol. 459-482).

13. GM, 18 de junio de 1779, p. 424. 
como sería el caso de la reimpresión de la Biblia Sacra Vaticana del año 1592 a cargo de la Real Compañía de Impresores y Libreros, cuyo anuncio en la Gaceta en enero de 1764 nos informa que, a fin de lograr la mayor exactitud en la edición,

[se] ha encargado su correccion a personas doctas, y zelosas, que desempeñaran su encargo con el mayor esmero; y para evitar toda errata, se pondrán los pliegos, como se vayan imprimiendo, a pública censura en la Librería de su Thesorero D. Angel Corradi, calle de las Carretas, quien pagará dos reales de vellon por cada una al primero que la advierta ${ }^{14}$.

Medida que es a un tiempo un inteligente recurso de márketing para atraer a los posibles compradores a la tienda y un eco del procedimiento empleado por los hermanos Foulis, de Glasgow, durante la impresión de su célebre Horacio de 1744.

Para alcanzar los libros de los estantes superiores, se utilizaba una escalera de catorce pies $-4,26$ metros- (su valor, 48 reales). La decoración interior se completaba con ocho sillas de paja dadas de verde con sus flores doradas a los respaldos, a ocho reales cada una (suman 64 reales), y un cuadrito de san José, pintado en el cristal de una tercia $-30,48 \mathrm{~cm}$.- (tasado en 24 reales). La tienda tenía un par de puertas vidrieras moldadas de diez pies de alto -3,04 metros(valoradas en 130 reales), que llevaban dieciséis vidrios cristales de media vara de largo y tercia de ancho -es decir, 41,7 por $30,4 \mathrm{~cm}$, a 9 reales con 4 maravedís cada uno incluyendo su emplomado (lo que representa un total de 160 reales). Teniendo en cuenta que Bailo entró a servir como mancebo mayor de Corradi en mayo de 1770 y había servido dicho puesto no sólo hasta la muerte del genovés, sino hasta el 14 de septiembre de 1777, podemos aventurar que, al menos en estos primeros meses tras hacerse con el local de su antiguo amo, mantendría básicamente la decoración de la antigua librería de Ángel Corradi.

Ángel Corradi pertenecía a la élite del comercio librero del Madrid de su época, los que eran denominados mercaderes de libros, es decir, aquellos que, paralelamente a la compra-venta de libros, aunaban las actividades de editor, haciendo imprimir obras de su cuenta para hacer comercio con ellas; de importador de libros del extranjero, ya fuese al por mayor o al detalle -haciendo uso para ello, en los primeros ańos, del nexo con el establecimiento familiar genovés, mediante su tío Repetto hasta la muerte de éste, y luego a través de su hermano Bartolomeo Corradi, activo al menos hasta 1783, que de algún modo siempre trabajó para él ${ }^{15}$-; y de distribuidor exclusivo de las obras de un autor

14. GM, 3 de enero de 1764, p. 8. La edición de esta Biblia se finalizó en 1767. Su corrector fue el oratoriano Juan de Aravaca.

15. A comienzos de marzo de 1770, B. Corradi elevó un memorial a los magistrados genoveses suplicando una rebaja en la suma que debía satisfacer en razón de impuesto patrimonial, alegando que «il poco suo traffico consisteva in fare qualche compra de libri a provigione per Angelo Corradi suo fratello libraro in Madrid, il quale, doppo i rumori, et abolizione de RR.PP. Gesuiti, e loro libri in Spagna, ha levato al supplicante ogni commissione proficua». Cit. en A. Petrucciani, art. cit., La bibliofilia, 96.2, 1994, p. 184. A comienzos de los ochenta, B. Corradi tuvo a su cargo las suscripciones genovesas a la edición paduana de la Encyclopédie méthodique. 
o institución, tanto a nivel peninsular y de las colonias españolas, como a nivel internacional ${ }^{16}$. Paralelamente a su actividad como mercader de libros, Corradi actuaba como girante de letras, aprovechando tanto su liquidez de capital, como su red de contactos peninsulares e internacionales con otros libreros y negociantes, entre los que cabe mencionar a Manuel Cavero Cortés, de la Compañía de Impresores y Libreros de Valencia, a los Cramer de Ginebra y al parisino Antoine Boudet ${ }^{17}$. En estas décadas, a todo aquel librero plenamente dedicado a la importación-exportación de libros le era imprescindible disponer de una red de contactos estratégicamente diseminados por toda la geografía peninsular y europea, pues sin ella no podía tener acceso a toda una gama de informaciones reservadas sobre proyectos, oportunidades editoriales y ocasiones de negocio; ni tampoco podía disfrutar de condiciones de intercambio y pago más favorables -tengamos en cuenta que a los socios comerciales habituales se les permite modificar los pedidos, retrasar los envíos y retrasarse en los pagos más allá de lo dispuesto por la ley- ${ }^{18}$. Corradi, durante los ańos setenta, estuvo relacionado con el hombre de negocios de origen genovés Juan Bautista Rossi, que pocos años después sería escogido como uno de los ocho directores iniciales del Banco de San Carlos. Su saber hacer en cuestiones de dinero lo pone de manifiesto la circunstancia de que sus colegas libreros le escogiesen como tesorero de la nueva Compañía de Impresores y Libreros del Reino, desde su fundación a finales de julio de 1763, hasta mayo de 1772, en que fue sustituido por el librero Bernardo Alverá.

Al librero Ángel Corradi no le unió una relación tan estrecha con la Academia de Bellas Artes de San Fernando, como la que mantuvo con la Real Biblioteca o con la Academia Española, pero a pesar de no haber ostentado nunca el cargo oficial de librero de dicha institución ilustrada, durante algunos años, entre finales de los cincuenta y mediados de los sesenta, se convirtió en uno de sus principales proveedores de libros y productos afines.

16. Para una tipología de los diferentes tipos de libreros madrileños, véase A. García Cuadrado, «La Compañía de Mercaderes de Libros de la Corte a mediados del siglo XVIII", Anales de Documentación, 4, 2001, p. 95-126. Para un ejemplo temprano de la posición intermediaria de Ángel Corradi entre el mercado nacional y el internacional, resulta ejemplar la carta que, con fecha 29 de junio de 1746, envía al librero pamplonés M.-A. Domech acerca de la posibilidad de que éste adquiriese algún juego completo de la nueva edición veneciana de Bollando, de la que ya habían salido 22 vols. Domech también había entrado en contacto directo con su tío Giacomo Filippo Repetto, ya entonces residente en Génova. Vid. carta n ${ }^{\circ} 16$ del apéndice 3 del libro de J. Itúrbide, Escribir e imprimir. El libro en el Reino de Navarra en el siglo XVIII, Pamplona, Gobierno de Navarra, 2007.

17. Para los Cramer, véase G. Barber, «The Cramers of Geneva and their trade in Europe between 1755 and 1766», en Studies on Voltaire, 30, 1964, p. 377-413.

18. En relación con las redes de libreros, resulta de gran interés el artículo de F. Inderwildi, "Géographie des correspondants de libraires dans la deuxième moitié du $18^{\mathrm{e}}$ siècle. La Société typographique de Neuchâtel, Cramer et Gosse à Genève», Dix-huitième siècle, 40, 2008, p. $503-522$. 


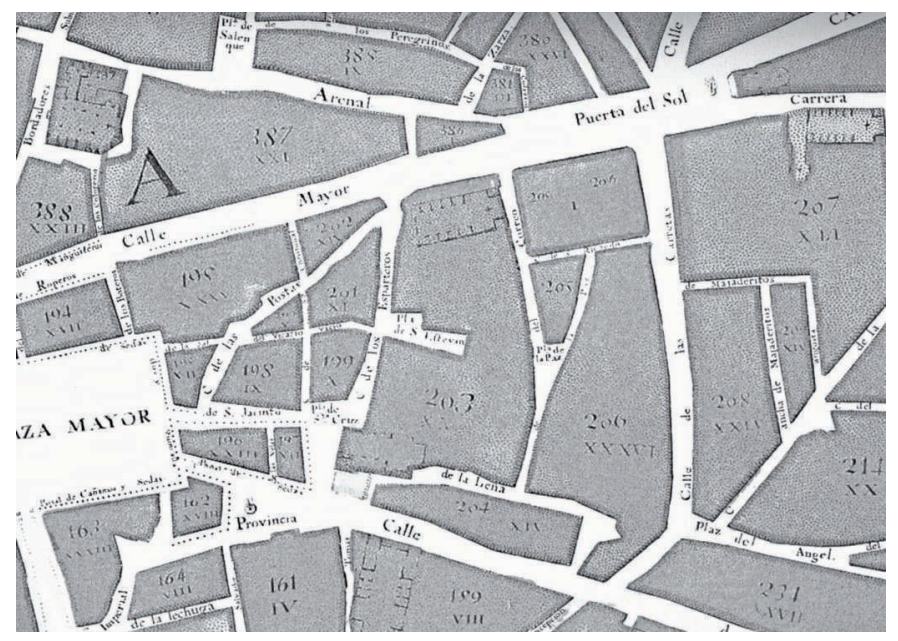

Fig. 1. - El área de la Plaza Mayor-Puerta del Sol, según el plano de Madrid de A. Espinosa de los Monteros (1769).

Por esos ańos, la Real Academia de las tres Nobles Artes -arquitectura, pintura y escultura- de San Fernando, estaba alojada en el espacioso piso principal de la Casa de la Panadería, de propiedad real, en el lado norte de la céntrica Plaza Mayor, domicilio ya de la Junta Preparatoria desde comienzos de 1745, y en que continuó tras recibir su impronta definitiva como fundación real el 12 de abril de 1752, bajo el reinado de Fernando VI.

La primera mención de una relación comercial entre la Academia y Corradi se halla en las actas de la junta particular de 21 de enero de 1759, en que, a propuesta del director y del teniente de la sección de arquitectura, Diego de Villanueva ${ }^{19}$ y José de Castañeda ${ }^{20}$, se aprobó la adquisición de un conjunto de obras que se consideraban precisas para la enseñanza de dicha materia ${ }^{21}$, de las

19. Diego de Villanueva (1715-1774), había sido nombrado director de arquitectura de la Academia de San Fernando el 7 de noviembre de 1756. Pocos años después editó la Regla de las cinco ordenes de Arquitectura de Vignola (Madrid, Joaquín Ibarra, 1764, fol.), que contiene 29 estampas dibujadas por él y grabadas por Manuel Rodríguez.

20. José de Castañeda, formado en Francia en la construcción de obras públicas, ocupó el 14 de abril de 1757 la tenencia de arquitectura de la Academia de San Fernando que había dejado vacante Diego de Villanueva. Castañeda se acreditó como excelente profesor de geometría y matemáticas de los alumnos de la Academia, para los que tradujo el Compendio de los diez libros de arquitectura de Vitrubio (Madrid, Gabriel Ramirez, 1761, 4º), a partir de la versión que Claude Perrault había hecho en francés.

21. «Los Directóres de Arquitectura [...] enseñarán y harán que estudien sus Discipulos por el método que aprobàre la Academia, sin variarlo con pretexto alguno. Les explicarán, é instruirán muy por menor en todas las Reglas teoricas y pràcticas, haciendo que tomen de memoria lo que juzgue conveniente. No admitirán en la Sala de Arquitectura al que no esté suficientemente instruido en la Geometria; en cuya Sala tampoco admitirán los Tenientes Discipulo alguno, que no haya aprendido á dibuxar bien. [...] Para que el estudio de esta Facultad se haga con el fruto y 
que por entonces había ejemplares disponibles en la librería del genovés en la madrileńa calle de las Carretas. Son las siguientes:

\begin{tabular}{|c|c|}
\hline Curs. mat. de Wolfio ${ }^{22}, 5$ tom. en $4^{\circ}$ de marq & 180 \\
\hline Comp. mat. de Tosca ${ }^{23} 9$ tom. en $8^{\circ}$ & 19 \\
\hline Todas las Obras de Mr. Beledor ${ }^{24} 6$ tom. en $4^{\circ}$ en marq & 40 \\
\hline Diction. mat. ${ }^{25} 2$ tom. en $4^{\circ}$ de marq & \\
\hline $\begin{array}{l}\text { Comp. de Wolf }{ }^{26} 3 \text { tom. en } 8^{\circ} \\
\text { Archit. de Rossi }{ }^{27} 2 \text { tom. en fol. grande }\end{array}$ & \\
\hline
\end{tabular}

aprovechamiento que tanto deseo, é importa, es mi voluntad que la Academia, reflexionando con maduréz esta materia, establezca un curso de Arquitectura, para que los Directores la enseñen metódicamente por dos, tres, ó mas ańos, segun á su prudente juicio parezca conveniente», en Estatutos de la Real Academia de S. Fernando, en Madrid, en Casa de D. Gabriel Ramirez, impresor de la Real Academia, 1757, p. 35-36.

22. En referencia a la obra de Christian Wolf, Elementa matheseos universae, Genevae, apud Henricum-Albertum Gosse \& Socios, 1743-1752, 5 vols., $4^{\circ}$, de la que el mismo libreroimpresor había sacado una edición anterior, prácticamente idéntica, en 1733-41. No se conserva ejemplar en la Biblioteca de la RABASF.

23. Compendio mathematico: en que se contienen todas las materias... de las ciencias que tratan de la cantidad que compuso... Thomas Vicente Tosca... del Oratorio de San Felipe Neri..., En Valencia, en la imprenta de Joseph Garcia. Se hallará en Valencia en la libreria de Manuel Cavero Cortés calle de Campaneros; y en Madrid en la de don Angel Corradi calle de las Carretas, 1757, 9 vols., $8^{\circ}$. Se conservan los ocho primeros vols. en la Biblioteca de la RABASF, encuadernados en pasta con hierros dorados en el lomo y cortes pintados, signaturas B-410 a B-417.

24. Debe aludirse aquí a las siguientes obras de Bernard Forest de Belidor (1691-1761), conservadas en la Biblioteca de la RABASF: Architecture hydraulique ou l'Art de conduire, d'élever et de ménager les eaux pour les différens besoins de la vie, París, chez Charles-Antoine Jombert, 1737, 4 vols., $4^{\circ}$, encuadernada en pasta, con hierros dorados en el lomo y cortes pintados (signaturas B-1670 a B-1673); La science des ingénieurs dans la conduite des travaux de fortification et d'architecture civile par..., París, chez Claude Jombert, 1729, 4º, encuadernado en pasta con filetes en seco, hierros dorados en el lomo y cantos y cortes pintados (signatura B-1685). El sexto volumen de los contenidos en esta referencia podría corresponder, a pesar de su distinto formato, al Dictionnaire portatif de l'ingénieur où l'on explique les principaux termes des Sciences les plus nécessaires à un Ingénieur sçavoir... par M. Belidor, París, chez Charles-Antoine Jombert, 1755, 8, encuadernado en pasta con hierros dorados en el lomo, filetes en seco y cortes pintados (B-2396).

25. Alude a la obra de Alexandre Saverien, Dictionnaire universel de mathématique et de physique ou l'on traite de l'origine, du progrès de ces deux Sciences \& des Arts qui en dépendent..., París, chez Jacques Rollin-chez Charles-Antoine Jombert, 1753, 2 vols., 4º. Se conserva en la Biblioteca de la RABASF (signatura B-2233 y B-2234), encuadernado en pasta con hierros dorados en lomo y cantos, y cortes pintados.

26. En referencia al Cours de mathématique: qui contient toutes les parties de cette science... par M. Chretien Wolf... traduit en françois \& augmenté considerablement..., París, chez CharlesAntoine Jombert, 1747-1753, 3 vols., $8^{\circ}$. De esta edición se conservan los tomos primero y tercero (signaturas C-2803 y C-2804), en la Biblioteca de la RABASF.

27. Se trata de la obra del grabador Domenico de Rossi, Studio d'Architettura Civile sopra gli Ornamenti di Porte e Finestre tratti da alcune Fabbriche insigne di Roma con le Misure Piante Modini, e Profili: opera de piu celebri architetti de nostri tempi..., Roma, Domenico de Rossi erede di Gio. Giac. de Rossi, 1702-1711, 3 vols., fol. Se conservan en la Biblioteca de la RABASF 3 vols. correspondientes a la parte primera y segunda de esta obra (signaturas C-1506, C-1498 y C-1507), faltando la tercera y última parte, del año 1721. 
Suman un total de 1669 reales de vellón, según la cuenta del secretario de la Academia José de Hermosilla ${ }^{28}$, cantidad que cobró Corradi de mano del conserje de la Academia, Juan Moreno Sánchez, el 3 de marzo de $1759^{29}$. Si observamos este conjunto, no llama la atención que de un total de ocho obras, cinco estén en francés, una en castellano, otra en italiano y una sola en latín, pues esto corresponde claramente con el sesgo modernizador y orientado a Europa -especialmente hacia Francia- de los estudios llevados a cabo en la Academia madrileńa. Temáticamente, cuatro de ellas son de matemáticas y las otras cuatro corresponden al área de la arquitectura-ingeniería. Sus formatos son el cuarto -cuatro casos-, formato usual en los manuales y el libro de estudio; el octavo -tres casos-, formato del libro de bolsillo; con un único caso de formato folio, correspondiente a una colección de unas doscientas estampas de arquitectura de edificios religiosos y seculares de la Roma moderna, pensada para su utilización en el aprendizaje de dicha materia a través de la observación y el comentario detenido.

La circunstancia de que Antonio Sancha gozase por entonces el cargo de librero de la Academia de San Fernando -Gabriel Ramírez, por su parte, poseía el título de impresor de la Academia-, no supuso ningún impedimento a la transacción, pues la Academia repartía sus adquisiciones entre un selecto grupo de libreros, entre los que cabe mencionar también al francés Joseph o José Orcel. En la misma junta particular de 21 de enero se acordó también encargar a Corradi que hiciese venir de París «las tres obras siguientes: Antiguedades de Roma por Mr. Desgodetz ${ }^{30}$, impresión de París; Paralelo de la Arquitectura antigua con la Moderna por Mr. Chambrey ${ }^{31}$, segunda edición; y el Diccionario de Arquitectura de Davillier ${ }^{32}$, edición de París de mil setecientos cincuenta y

28. Ignacio de Hermosilla y Sandoval, hermano del ingeniero y arquitecto José de Hermosilla, sirvió el puesto de secretario de la Academia de Bellas Artes de San Fernando entre el 11 de noviembre de 1753 y el 1 de septiembre de 1776, en que pasó a ser oficial segundo de la secretaría del despacho de Indias.

29. Véanse los recibos en "Cuentas del año 1759", fechadas por J. Moreno Sánchez en 21 de enero de 1760, Libros de cuentas de la RABASF, signatura 3-201. Moreno Sánchez fue el conserje de la Academia entre el 2 de mayo de 1745 y su muerte, con ochenta ańos, en enero de 1795, y estaba encargado de la venta de las medallas acuñadas por la Academia, y de las estampas y libros publicados por los académicos.

30. Debe ser la obra de Antoine Desgodetz, Les edifices antiques de Rome dessinés et mesurés tres exactement par Antoine Desgodetz architecte, París, chez Jean Baptiste Coignard imprimeur du Roy, 1682, fol. La Biblioteca de la RABASF posee un ejemplar de esta obra (signatura C-298), con exlibris de Brunner de Vendelincour.

31. Se trata aquí de Roland Fréart de Chambray, Parallèle de l'architecture antique et de la moderne, contenant les profils des plus beaux édifices de Rome comparés avec les dix principaux auteurs qui ont écrit des cinq Ordres, sçavoir Palladio et Scamozzi, Serlio et Vignole, D. Barbaro et Cataneo, L.B. Alberti et Viola, Bullant et de L'Orme. Seconde édition augmentée de piédestaux de chaque ordre suivant l'intention des mêmes auteurs, París, chez Charles Anthoine Jombert, [s.a.: hacia 1750], fol. En la Biblioteca de la RABASF se conserva un ejemplar sin portada de la traducción inglesa de 1664 debida a J. Evelyn (signatura B-1640).

32. Es referencia a la obra de Augustin-Charles d'Aviler, Dictionnaire d'architecture civile et hydraulique et des arts qui en dépendent: Comme la Maçonnerie, la Charpenterie..., París, chez 
cuatro». Si examinamos estas primeras adquisiciones y encargos de libros, nos llama la atención la presencia mayoritaria de obras - siete de once- publicadas por el impresor-librero parisino Charles-Antoine Jombert (1712-1784), con tienda abierta en la orilla izquierda del Sena, en el barrio de la Universidad, concretamente en la rue Dauphine à l'image Notre-Dame, calle que desemboca en el Pont Neuf. Jombert había heredado el negocio de su padre Claude Jombert en 1735, y cimentaba su negocio en la edición de manuales de arquitectura, matemáticas y fortificación, gran parte de ellos destinados a las escuelas de artillería y de ingenieros militares, por lo que gozaba del título de «libraire du Roi pour l'artillerie \& le Génie», tal como rezan sus portadas ${ }^{33}$. Es indudable que Corradi debió tener establecida algún tipo de relación directa o indirecta con Jombert para la venta de sus libros a través de su librería madrileńa.

El 20 de abril de 1759, a instancias de los profesores encargados del curso de arquitectura, se hizo entrega a Corradi de una nueva lista de libros e instrumentos matemáticos, entre los que se mencionan «un juego de globos, con su esfera armilar, de dos pies de diámetro montados con sus brújulas. Un grafómetro con su brújula. Una plancheta. Un nivel de agua con su pie, y dos estuches de matemática para la mesa ${ }^{34}$. Para sastisfacer estos encargos, Corradi se sirvió del impresor-librero parisino Antoine Boudet (1717-1787), su principal corresponsal en París ${ }^{35}$. Boudet, vástago de una dinastía de libreros lioneses, era hijastro de Jean-Baptiste III Coignard, impresor de la Académie Francaise, en cuya imprenta entró como aprendiz en 1729, siendo recibido como librero en 1734 y como impresor en 1742, integrándose finalmente en el negocio de su padrastro y su cuñado Pierre Gilles le Mercier, situado en la rue St. Jacques, donde abrirá su propia librería à la Fontaine d'or, frente a la rue des Mathurins. Boudet comenzó a hacer su fortuna a comienzos de los cuarenta con el periódico Petites affiches de Paris, prosiguiendo su éxito comercial con el Journal économique, publicado entre 1751 y 1772, que estaba consagrado a la agricultura y el comercio entre Francia y el extranjero, y prestaba particular atención a España. En 1750 sucedió asimismo a su padrastro como libreroimpresor de la universidad de París. Para afrontar la impresión de todos estos trabajos había adquirido en 1743 la imprenta de Simon Langlois, con seis prensas, a las que añadió una más en 1769 , contando, a partir de 1755, para guardar sus existencias con dos almacenes en el cercano convento dominico de los Jacobinos, que se convirtieron en tres en 1769.

Charles-Antoine Jombert, Imprimeur-Libraire, 1755, fol. Hay un ejemplar en la Biblioteca de la RABASF (signatura B-1727), encuadernado en pasta.

33. C. Bousquet-Bressolier, "Charles-Antoine Jombert (1712-1784). Un libraire entre sciences et arts», Bulletin du bibliophile, 2, 1997, p. 299-333.

34. Vid. acta de la junta particular de la RABASF de 29 de julio de 1768.

35. Para Boudet, vid. F. Barbier, S. Juratic y A. Mellerio, Dictionnaire des imprimeurs, libraires et gens du livre à Paris (1701-1789): A-C, Ginebra, Droz, 2007, p. 274-280 y P. J. Guinard, «Le livre dans la Péninsule Ibérique au XVIII" siècle. Témoinage d'un libraire français», Bulletin Hispanique, 49, 1957, p. 176-198. 
De los libros encargados a Corradi en abril de 1759, a mediados de diciembre «sólo han venido cinco en una remesa de treinta y cuatro que le ha llegado de París». Examinada dicha lista por Villanueva y Castañeda, éstos escogieron otros dos más que juzgaron útiles; por su parte, los «instrumentos que se encargaron [...] no han venido ${ }^{36}$. A mediados de 1760 llegaron a la Academia los globos, el grafómetro, el nivel de agua y los estuches, pero todo «muy falto y mal acondicionado. De suerte que para completarlo y que pudiese ser de uso, se mandó á Castañeda poner una lista de las piezas que faltaban. La puso y firmó en 30 de junio de 60, y contenía: el nivel que falta en el grafómetro y sirve para horizontarle. Los mapas de África, Asia y América con el mapamundi, compañeros del de Europa, que vino solo. La calota o casco esférico ${ }^{37}$ para el uso de los globos, citada al folio 112 del librito que trata de él ${ }^{38}$. Media docena de cañones de cristal para el nivel, a fin de reemplazar los que se rompan. La memoria para armar y desarmar el grafómetro. La esfera armilar, que ha de ser de cobre y bastará ser de cerca de un pie de diámetro» ${ }^{39}$. La memoria de Castañeda se entregó a Corradi, advirtiéndole «que no menos

36. Junta ordinaria de 18 de diciembre de 1759, en Actas de sesiones ordinarias, ańo 1759, fol. 69v., RABASF.

37. Las calotas, calotas polares, cascos o casquetes esféricos eran las partes superior e inferior de la superficie de la esfera terráquea al ser cortada por un círculo cualquiera correspondiente a una latitud determinada. En la fabricación de globos terráqueos eran imprescindibles en conjunción con los husos correspondientes a los meridianos, a fin de dar a dichos globos un mejor acabado.

38. Se alude aquí al libro de Robert de Vaugondy, Usages des globes celeste et terrestre..., París, chez Antoine Boudet, Imprimeur du Roi, rue S. Jacques, à la Bible d'Or, 1751, 12º, en cuyo capítulo titulado Description et usage du sphérico-gonometre, podemos leer efectivamente lo siguiente: "Cet instrument, auquel on pourroit donner le nom de Raporteur sphérique, est une demi-calote de cuivre, dont la surface intérieure doit s'appliquer éxactement sur celle du globe auquel on la destine. Cette demi-calote est évuidée pour qu'elle soit plus légére, \& qu’on puisse voir les constellations sur lesquelles on veut l'appliquer. Son rayon doit être à peu près un arc de vingt à vingt-cinq degrés. Au centre de cet instrument, est une ouverture d'environ un demi-pouce de diamêtre, sur laquelle est soudé un canon de trois à quatre lignes de hauteur, éxactement tourné, \& dont l'axe doit être perpendiculaire à la surface sphérique. Ce canon en reçoit extérieurement un autre auquel est soudé une alidade.» (p. 112-113). La Biblioteca de la RABASF contiene un ejemplar de esta obra -signatura B-2383-, que todavía conserva sus cinco estampas plegadas. En 1758 Diego de Torres Villarroel y su sobrino Isidoro Ortiz Gallardo y Villarroel lo habían traducido - Uso de los globos, y la sphera, escrito por M. Robert Vaugondi, traducido de frances en castellano, extractado, y aumentado por los Cathedraticos de Mathematicas de la Universidad de Salamanca el Doct. D. Diego de Torres Villarroel y el Doct. D. ..., Salamanca, por Eugenio García de Honorato y S. Miguél impressor de dicha Universidad, [1758], 4º - con el propósito de que sirviese de manual en una academia o estudio práctico que enseñase a los curiosos el manejo de las esferas terráquea y celeste recientemente adquiridas por la biblioteca universitaria de Salamanca. El proyecto de Torres y su sobrino, que le había sustituido en la cátedra de matemáticas de la que se había jubilado, se encontró con la oposición frontal de los catedráticos más tradicionalistas, opuestos a la idea de una academia abierta al público y a la traducción en lengua vulgar, y no en latín, del manual de Vaugondy. El claustro salmantino, en su sesión plenaria de 11 de mayo de 1758, desautorizó el proyecto de los Villarroel, que trasladaron el enfrentamiento a Madrid, disponiendo finalmente el Consejo Real en julio de 1762 que se organizasen los estudios planeados por Torres.

39. Citamos a partir de aquí del acta de la Junta particular de 29 de julio de 1768, RABASF. 
que los instrumentos, eran faltos y mal acondicionados muchos de los libros que había enviado. Satisfizo con que así se los enviaba Budet. Y Castañeda, de orden del Señor Viceprotector ${ }^{40}$, le previno cortase todos los encargos que a éste tuviese hechos, con expresión de que ya no se necesitaba la esfera armilar y, últimamente, que presentase la cuenta de todo. Desde el mismo año de 60 repetí yo [Ignacio de Hermosilla] varias veces a Corradi este encargo de la cuenta, y siempre me respondió la formaría quando Budet acabase de enviar lo que le estaba pedido». La cuenta detallada de los libros, globos e instrumentos, de sus portes y derechos, la presentó al fin Corradi el 12 de agosto de 1762, ascendiendo a un total de siete mil quinientos setenta y tres reales de vellón. Es la siguiente:

No 15. Cuenta de Angel Corradi de varios libros, instrumentos matemáticos y globos que de París ha traido y entregado para la Real Academia de San Fernando ${ }^{41}$

Vida de pintores sacadas de Palomino ${ }^{42} 1$ tomo $8^{\circ}$ Londres

Gautiée ${ }^{43}$ Traité des ponts 2 tomos $8^{\circ}$ en pasta

Durand ${ }^{44}$ Architecture des voûtes 1 tomo folio pasta

Vingbons $s^{45}$ Architecture 1 tomo folio

De la Hire ${ }^{46}$ Art de charpenterie 1 tomo fol.

40. Tiburcio de Aguirre y Ayanz de Navarra ocupó el cargo de Viceprotector de la Real Academia de San Fernando entre el 27 de abril de 1753 y el 25 de mayo de 1767, en que falleció.

41. En «Cuentas del año 1762», fechadas por J. Moreno Sánchez a 2 de marzo de 1763, Libros de cuentas de la RABASF, signatura 3-204.

42. Antonio Palomino y Velasco, Las vidas de los pintores y estatuarios eminentes españoles. Que con sus heroycas obras han ilustrado la Nacion: y de aquellos Estrangeros Ilustres, que han concurrido en estas Provincias, y las han enriquecido, con sus eminentes Obras, Londres, impresso por Henrique Woodfall a costa de Claude du Bosc \& Guilliermo Darres en el Mercado de Heno, 1742, $8^{\circ}$. Obra conservada en la Biblioteca de RABASF (signatura A-1317). Encuadernada en pasta con hierros dorados en el lomo y cortes jaspeados.

43. Alude seguramente a las siguientes obras de Hubert Gautier, Traité des ponts où il est parlé de ceux des romains \& de ceux des modernes..., París, chez Duchesne, 1755, 80 y Traité de la construction des chemins où il est parlé de ceux des romains \& de ceux des modernes..., Paris, chez Duchesne, $1755,8^{\circ}$, conservadas en la Biblioteca de la RABASF con las signaturas B-1821 y B-1820, respectivamente; encuadernadas en pasta con hierros dorados y cortes pintados.

44. Podría tratarse de la obra de François Derand, L'Architecture des voûtes, ou l'art des traits et coupes des voûtes, París, Duchesne, 1755, fol., que no se encuentra en la Biblioteca de la RABASF.

45. Philippe Vingboons, Euvres d'architecture, contenant les desseins tant en plans qu'en elevations, des principaux, \& des plus nouveaux batimens... de la Ville d'Amsterdam... Ordonnez par Philippe Vingboons; Divisées en deux Tomes. Tome Premier, La Haya, chez Pierre de Hondt, 1736, fol. Ejemplar conservado en la Biblioteca de la RABASF (signatura C-1522), encuadernado en pasta con hierros dorados en lomo y cantos.

46. Mathurin Jousse, L'Art de charpenterie de Mathurin Jousse; corrigé et augmenté de ce qu'il $y$ a de plux curieux dans cet Art et des Machines les plus necessaires à un Charpentier par M. de la Hire, París, chez Charles-Antoine Jombert, 1751, fol. Ejemplar conservado en la Biblioteca de la RABASF (signatura B-2899bis); encuadernado en pasta con filetes en seco, hierros dorados en lomo y cantos, y cortes pintados. 
Gauger ${ }^{47}$ Traité des cheminées 1 tomo $8^{\circ} \quad 10$

Dictionnaire d'Architecture ${ }^{48} 1$ tomo $4^{\circ}$

Montucla ${ }^{49}$ Histoire des mathématiques 2 tomos $4^{\circ} \quad 105$

Jeaurat ${ }^{50}$ Perspective 1 tomo $4^{\circ} \quad 60$

Nouveaux principes de perspective linéaire ${ }^{51} 1$ tomo $8^{\circ} \quad 12$

Du Pain ${ }^{52}$ Science des ombres 1 tomo $8^{\circ} \quad 18$

Palais de Genes par Rubens ${ }^{53} 1$ tomo folio $\quad 180$

Bion $^{54}$ instrumens de mathématique 1 tomo $4^{\circ} \quad 60$

Laugier ${ }^{55}$ Architecture 1 tomo $8^{\circ} \quad 20$

Courtonne ${ }^{56}$ Perspective pratique 1 tomo folio $\quad 66$

Blondel $^{57}$ Discours d'Architecture 1 tomo $8^{\circ} \quad 20$

Caylus $^{58}$ Antiquités Egyptiennes 2 tomos $4^{\circ} \quad 180$

47. Nicolas Gauger, La mecanique du feu, ou L'art d'en augmenter les effets, \& d'en diminuer la dépense: contenant le Traité des nouvelles cheminées Qui échauffent plus que les cheminées ordinaires \& qui ne sont point sujettes a fumer, \& co par..., París, chez C. A. Jombert, Libraire, 1749, 8. Ejemplar conservado en la Biblioteca de la RABASF (signatura B-2167), encuadernado en pasta con hierros dorados, filetes en seco y cortes pintados.

48. Es la obra de d'Aviler a la que se hizo referencia anteriormente.

49. Jean Etienne Montucla, Histoire des mathematiques... par M. Montucla, París, chez Charles-Antoine Jombert, 1758, 2 vols., 4º. Se conserva en la Biblioteca de la RABASF (signatura C-450).

50. Edme-Sebastien Jeaurat, Traité de perspective a l'usage des artistes, París, chez CharlesAntoine Jombert, 1750, 4\% . Ejemplar conservado en la Biblioteca de la RABASF (signatura A-641), encuadernado en pasta con hierros dorados en el lomo.

51. Brook Taylor y Patrick Murdoch, Nouveaux principes de la perspective linéaire: traduction de deux ouvrages, l'un anglois, du docteur Brook Taylor, l'autre latin de M. Patrice Murdoch, avec un essai sur le Mélange des couleurs par Newton avec figures..., Amsterdam, chez Westein, 1757, $8^{\circ}$. Se conserva en la Biblioteca de la RABASF (signatura B-1050), encuadernada en pasta con hierros dorados en lomo y cantos y cortes pintados.

52. Louis Charles Dupain de Montesson, La science des ombres, par rapport au dessein: Ouvrage nécessaire à ceux qui veulent dessiner l'Architecture Civile et Militaire ou qui se destinent à la Peinture..., París, chez Charles-Antoine Jombert, 1750, $8^{\circ}$. Se conserva en la Biblioteca de la RABASF (signatura B-2096). Encuadernación en pasta con hierros dorados en el lomo y cantos, filetes en seco y cortes pintados.

53. Peter Paul Rubens, Architecture Italienne: contenant les plans et les elevations des plus beaux palais et edifices de la ville de Genes levé et dessiné par... P. P. Rubbens, Amsterdam-Leipzig, chez Arkstee et Merkus, 1755, fol. Se conserva en la Biblioteca de la RABASF (signatura B-2680), encuadernado en pasta con hierros dorados en el lomo.

54. Nicolas Bion, Traité de la construction et des principaux usages des instrumens de mathématique: avec les figures nécessaires pour l'intelligence de ce traité..., París, chez Charles-Antoine Jombert... et Nion fils, 1752, 4º. Ejemplar conservado en la Biblioteca de la RABASF (signatura C-449).

55. Marc-Antoine Laugier, Essai sur l'architecture, París, Duchesne, 1753, 8º. El ejemplar conservado en RABASF lleva un ex-libris del marqués de Ovando, por lo que es posible que no se trate del ejemplar aludido en la cuenta.

56. Jean Courtonne, Traité de la perspective pratique avec des remarques sur l'architecture: suivis de quelques Edifices considerables mis en Perspective \& de l'invention de l'Auteur..., París, chez Jacques Vincent, 1725, fol. Obra conservada en la Biblioteca de la RABASF (signatura B-2898); encuadernación en pasta con hierros dorados en lomo y cantos, filetes en seco y cortes pintados.

57. Jacques François Blondel, Discours sur la nécessité de l'étude de l'architecture: dans lequel on essaie de prouver, combien il est important pour le progrès des arts..., París, chez C. A. Jombert, $1754,8^{\circ}$. No se encuentra en la Biblioteca de la RABASF.

58. Se trata de la obra del conde de Caylus, Recueil d'antiquités egyptiennes, etrusques, grecques 
Bullet ${ }^{59}$ Architecture pratique 1 tomo $8^{\circ}$

Abregé de Vitruve ${ }^{60} 1$ tomo $8^{\circ}$

Calepinus $^{61}$ Septem linguarum 2 tomos folio en uno $\quad 60$

Vitrubio $^{62}$ con le note del Marchese Galiani 1 tomo folio $\quad 150$

Sacre de Louis $\mathrm{XV}^{63}$ grande in folio en tafilete

2 globos de Mr. Robert montados y guarnecidos su costo

en París, libras tornesas

Cajones y embalaje de los mismos, libras

Comisión y gastos en París pagados a Boudet

$\underline{70}$

Libras de Francia

586

Que hacen reales de vellón

Suma reales vellón

Lista de los instrumentos

1 Graphometre $^{64} \quad$ libras de Francia

1 Niveau $^{65}$

et romaines, París, chez Desaint \& Saillant, 1752-1764, 6 vols., 4º. Posiblemente en la cuenta se haga alusión a los primeros dos tomos. El segundo de éstos fue impreso por Duchesne en 1756. En la Biblioteca de la RABASF se encuentra la serie completa (signaturas B-694 a B-699), encuadernada en pasta con hierros y cortes dorados.

59. Pierre Bullet, L'Architecture pratique, qui comprend la construction générale \& particuliere des Bâtimens..., París, chez Didot, 1755, 8º. Obra conservada en la Biblioteca de la RABASF (signatura B-1776), encuadernada en pasta con hierros dorados en lomo y cantos y cortes pintados.

60. En la Biblioteca de la RABASF (signatura B-2374), se conserva un Abregé des dix livres d'Architecture de Vitruve, París, chez Jean-Baptiste Coignard, 1674, 8º, encuadernado en pasta.

61. Ambrogio Calepino, Septem linguarum Calepinus hoc est lexicon latinum, variarum linguarum interpretatione adjecta in usum Seminarii Patavini, Patavii, Typis Seminarii apud Joannem Manfrè, 1752, 2 vols., fol. El ejemplar de esta obra conservado en la Biblioteca de RABASF se conserva encuadernado en pergamino en 2 vols. (signaturas B-2194 y B-2195).

62. M. Vitrubio Polión, L'Architettura di M. Vitruvio Pollione colla traduzione italiana e comento del marchese Berardo Galiani... dedicata alla Maestá di Carlo Re delle Due Sicilie..., Nápoles, nella Stamperia Simoniana, 1758, fol. Obra conservada en la Biblioteca de la RABASF (signatura B-829), encuadernada en pasta con hierros dorados en el lomo y cortes pintados.

63. Parece referencia a la obra en gran folio Sacre de Louis XV dans l'église de Reims, le 25 octobre 1722, [París, 1723], que contiene 30 estampas sobre papel de Holanda, en algunos ejemplares iluminadas a mano. El ejemplar conservado en la Biblioteca de RABASF (signatura A-1613), se halla encuadernado en tafilete, profusamente decorado con hierros dorados en cubierta, lomo y canto, escudo real dorado en cubiertas anterior y posterior, y cortes dorados. El famoso encuadernador Antoine-Michel Padeloup encuadernó un número limitado de ejemplares en tafilete con adornos a la dentelle, destinados al obsequio de personalidades.

64. Define el lexicógrafo Terreros, «GRAFO-METRO, instrumento Matemático, que se reduce á un semicirculo dividido en 180 grados con su alidada, que le atraviesa, pinulas para la visual, \&c. y una brujula. Fr. Graphometre. Lat. Graphómetrum. El instrumento á que unos llaman plancheta, y otros meseta, viene á ser lo mismo que el grafo-metro, uno, y otro se mueven sobre una rodilla, ó bola, que encaja en cierta porcion de circulo para el facil uso de la máquina.» (en Diccionario castellano con las voces de ciencias y artes, 1788).

65. El jesuita Terreros, en su voz NIVEL, aclara que «Hai muchas especies de Niveles, con particularidad se toma por un instrumento que usan los Jeómetras, para tirar una linea paralela al Orizonte. Fr. Niveau. Lat. Libramen, libella. It. Archipenzolo: El asiento del nivel que usan comunmente, se llama chambrana, las tablas, ó montantes que suben desde la chambrana, se 
1 Alidade $^{66}$ et planchette ${ }^{67} \quad 102$

2 Étuis de mathématiques ${ }^{68} \quad 100$

1 Les trois pieds a branches ${ }^{69}$

Cajón en que venían y gastos en París 69

Porte de París a Nantes de éstos y de los

globos abonados a Boudet $\quad \underline{24}$

libras de Francia $\quad 676$

Que hacen reales de vellón $\quad 2704$

Gastos y fletes de tres cajones hasta Bilbao de estos

instrumentos y globos reales vellón 173

Portes de los mismos de Bilbao a Madrid reales vellón $\quad \underline{191}$

Suma el todo reales de vellón $\quad \frac{191}{7573}$

Ángel Corradi [rubricado]

Madrid a 12 de agosto de 1762

Revisada la cuenta de estos libros e instrumentos por José de Castañeda - «Unos y otros se han pedido como útiles e indispensables para su instituto [la sección de arquitectura de la Academia], y los precios a que están cargados me parecen arreglados especialmente los libros»-, se abonaron a Corradi los siete mil quinientos setenta y tres reales de vellón de su importe con fecha 18 de septiembre de 1762. Curiosamente, la factura precisa que los tres cajones con los instrumentos y globos llegaron de París a Madrid por la ruta Nantes-Bilbao,

llaman largueros, ó pies derechos, la tabla que afirma la obra por la parte superior Zapata, la cama en que entra el perpendiculo, Caja, el clavo que la afirma por la parte inferior, estaquilla, y si pasa horizontalmente, pasador, Esp. t. 9.»

66. Según Terreros, «ALHIDADA, ó ALIDADA, termino de Jeometria, y Astronomia, es una regla puesta sobre el Astrolabio, Grafometro, ó Plancheta. Fr. Alhidade, ó Alidade. Lat. Dioptra, versatilis regula, el Lat. Dioptra, es tomado del Griego oío $\pi \tau \rho \alpha$ y aunque el nombre de Alhidada es Arabe, se ha comunicado á casi todas las Naciones. En medio de la Alhidada está la linea fiducial, y al cabo tiene por una, y otra parte dos pinulas para observar. Esp. t. 9."

67. «La plancheta es el mas acomodado, y tal vez el mas antiguo de los instrumentos inventados para esta operación [de medir ángulos sobre el terreno]. Compónese de una tablita muy acepillada, igual, de pie y medio en quadro, al poco mas ó menos, puesta sobre tres pies, y movible en diferentes direcciones, de modo que se la puede poner inclinada al orizonte. Las planchetas mejores son las que se pueden mover desahogadas ácia qualquiera direccion, manteniéndose firmes en la inclinacion que se les da; y son sólidas y fuertes de modo que no se descompongan ni venzan con el frio, el calor, y los tiempos húmedos y secos.» (B. Bails, Principios de Matemática de la Real Academia de San Fernando por... Quarta Edicion, añadida. Tomo I, Madrid, en la Imprenta de la Hija de D. Joaquin Ibarra, 1805, p. 471).

68. Los contenidos de semejantes estuches de matemáticas estaban estandarizados ya en la época, como nos revela un autor como Genssane en su libro La géométrie souterraine ou traité de géométrie-pratique appliqué a l'usage des travaux des mines (Montpellier, 1776): "De l'Étui de Mathématiques: Cet Étui doit être garni d'un compas simple, d'un compas à trois pointes, d'un porte-crayon, d'un tire-ligne avec une aiguille à ponctuer, d'une règle, d'un compas de proportion, d'une équerre pliante ave un oeil pour servir de niveau au besoin, d'un plomb \& de deux demi-cercles gradués, vulgairement appellés rapporteurs, $\&$ dont l'un doit être de métail, $\&$ l'autre de corne, pour qu'il soit transparent; ce dernier sur-tout est d'une grande commodité pour porter sur le papier les différens angles qu'on a pris en opérant» (p. 37).

69. Es decir, un trípode extensible. 
por lo que habría que considerar el seguro marítimo entre los gastos asociados a los fletes, que solía variar entre el 2 y el 8 por ciento según la situación políticomilitar, que a partir de 1761 era de guerra, al haber entrado España en la de los Siete Años del lado de Francia. No obstante, la travesía del Golfo de Vizcaya nunca podría compararse entonces con el riesgo de la ruta entre Cádiz y la América Española ${ }^{70}$.

Sin lugar a dudas las piezas más llamativas de todo este conjunto son la pareja de globos terrestre y celeste, realizados por los cartógrafos parisinos Gilles Robert de Vaugondy (1686-1766) -que solía firmar sus obras como «M. Robert»-, y su hijo, Didier Robert de Vaugondy (1723-1786), géographes ordinaires du Roy, con tienda abierta en el quai de l'Horloge du Palais, junto a la Île de la Cité, en la que vendían sus colecciones de mapas, estampas sueltas de éstos y globos.

Fig. 2. - El globo terrestre de Robert de Vaugondy importado por la Real Academia de Bellas Artes de San Fernando. Facultad de Bellas Artes de la Universidad Complutense.

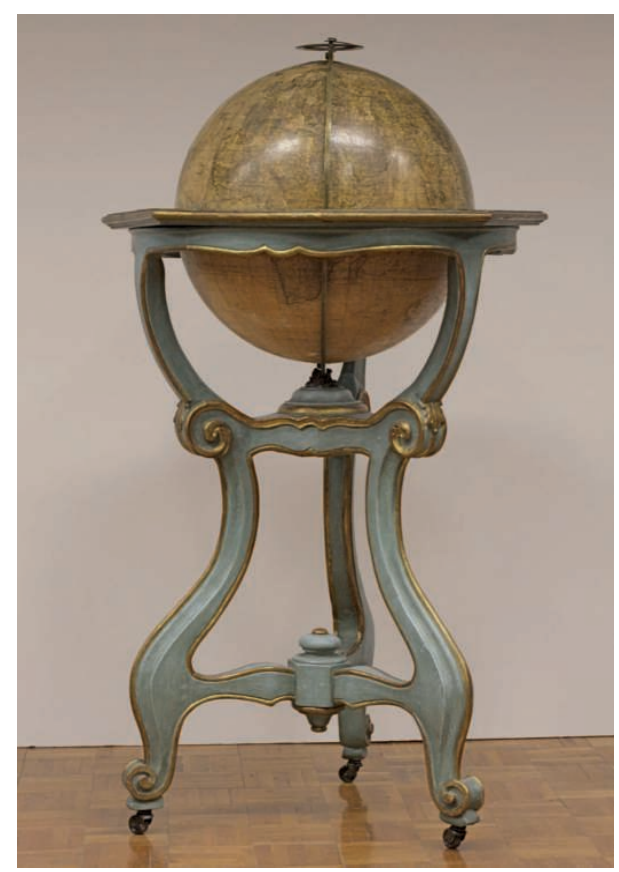

Estos últimos se fabricaban en distintos tamaños, encolando piezas triangulares de tela conteniendo fragmentos estampados sobre una base de papier-mâché retocada con escayola. Su maestría en la construcción de globos fue reconocida por Diderot, que le encargó la redacción del artículo «Globes» en el tomo VII de la Encyclopédie $e^{71}$. Significativamente, el librero Antoine Boudet estuvo

70. Recuérdese en este sentido cómo el ginebrino François Grasset, uno de los más activos exportadores de libros suizos al mercado ibérico, le advertía a Albert de Haller en carta de 30 de enero de 1762, que «les Indes se trouvant par ce fâcheux événement fermées, il n’y eut presque plus moyen de se procurer des commissions de livres», citado por G. Bonnant, "La librairie genevoise dans la Péninsule Ibérique au XVIII" siècle», Genava, 9, 1961, p. 103-124, en p. 116, nota 70 .

71. Sobre los Vaugondy, deben consultarse los artículos de M. Sponberg Pedley, «The Map Trade in Paris, 1650-1825», Imago Mundi, 33, 1981, p. 33-45 y "New Light on an Old Atlas: 
asociado con el cartógrafo Robert de Vaugondy, al que financió la publicación del Atlas Universel de 1757, compuesto por ciento ocho mapas (tres de ellos plegados, el resto a doble página), que fue la primera obra en su género que vio la luz en Francia mediante suscripción pública.

Los globos, producidos en papel y yeso, con meridiano y círculo horario metálico, tienen una altura de $116 \mathrm{~cm}$. y un diámetro de $46 \mathrm{~cm}$., descansando sobre una cazoleta octogonal sostenida en las abrazaderas que prolongan los pies de un trípode de madera sobre ruedas. Los pies, reforzados por tres sencillos travesaños, dibujan un perfil ondulado en «ese» y «contraese» típicamente rococó, con extremos rematados en volutas. Los globos que recibió la Academia de San Fernando pertenecen a la serie original de 1751, que se reprodujo en 1764 y 1773. A España llegaron algunos ejemplares más. La Universidad de Salamanca adquirió una pareja de globos terrestre y celeste que llegaron a dicha institución en enero de $1758^{72}$, de los que se conserva el celeste, expuesto en la Antigua Biblioteca ${ }^{73}$. Son muy pocos los ejemplares, especialmente aquellos de la tirada de 1751, que han sobrevivido hasta nuestros días, alcanzando en la actualidad precios muy altos en las subastas ${ }^{74}$. Los globos que adquirió la Real Academia de San Fernando se conservan todavía, pero ya no en la Academia, sino en colección artística de la Facultad de Bellas Artes de la Universidad Complutense de Madrid ${ }^{75}$.

Documents concerning the Publication of the Atlas Universel (1757)», Imago Mundi, 36, 1984, p. 48-63, y su libro Bel et Utile: The Work of Robert de Vaugondy Family of Mapmakers, Tring, Map Collector Publications, 1992.

72. Libros de Claustros, AUS 225, fol. 13v-15v. Vid. J.-L. Polo Rodríguez, «Reformas en la Universidad de Salamanca de los primeros Borbones (1700-1759)», Espacio, Tiempo y Forma, 7 , 1994, p. 145-174, en p. 169.

73. J. Ramón Nieto González y E. Azofra Agustín, Inventario artístico de bienes muebles de la Universidad de Salamanca, Salamanca, Ediciones Universidad de Salamanca, 2002, n 323, p. 291.

74. En la subasta celebrada en Christie's de Mónaco el 29-30 de abril de 2000, lote 75, se vendió una pareja de globos terrestre y celeste de mano de R. de Vaugondy, pertenecientes a la colección del modisto Karl Lagerfeld por algo más de doscientos ochenta mil dólares. Las Arader Galleries de Nueva York han puesto recientemente en venta otra pareja de esferas de Vaugondy -no queda claro si son de las fabricadas en 1751- por un precio cercano al millón de dólares, dicha pareja se había vendido previamente en Sotheby's de Nueva York el 24 de mayo de 2007 por la suma de cuatrocientos cincuenta mil dólares. Vid. http://www.biblio. $\mathrm{com} /$ atlases-rare-maps/a-pair-of-louis-xv-terrestrial-and-didier-robert-de-vaugondy-17231751 ctbk-567f9 -162925369, consultado el 25 de mayo de 2010.

75. Patrimonio Histórico Artístico de la Universidad Complutense, no inv. CUC 571, con inscripciones GLOBE CELESTE dressé par ordre DU ROI et calculé pour l'année 1770 par le Sr Robert de Vaugondy fils, Avec approbation de l'Académie Royale des Sciences. Aout 1751. En la parte inferior de la esfera hay otra cartela con la inscripción A PARIS / chés L'AUTEUR sur / le Quay de L'horloge / du Palais. La esfera terrestre, CUC 591, lleva la inscripción GLOBE TERRESTRE dressé par ordre DU ROI par le Sr Robert de Vaugondy fils. Avec l'approbation de l'Académie Royale des Sciences. Aout 1751. En otra cartela, en la parte inferior, se lee A PARIS / chés L'AUTEUR Quay / de L'horloge / du Palais. La localización actual de los globos de Vaugondy en la Facultad de Bellas Artes de la Universidad Complutense deriva del cambio de sede de la Escuela Superior de Bellas Artes de San Fernando, que abandonó el edificio de la calle Alcalá hacia 1967, pasando a la Ciudad Universitaria. Con el traslado se transfirió el material que los profesores entendieron 
Por lo que respecta a los libros, de un total de veintiuna nuevas obras incluidas en este envío, quince-el 71 por ciento-son francesas y, de éstas, siete, algo menos de la mitad, han salido de las prensas de Charles-Antoine Jombert; tres -el 14 por ciento- proceden de los Países Bajos; dos -el 10 por ciento- se han impreso en distintos estados de Italia, y solamente una -un magro 5 por ciento-, ha visto la luz en Inglaterra, resultando llamativo de este caso el que se trate de una obra impresa en Londres en lengua castellana. Examinando sus formatos, nos hallamos ante ocho folios, cuatro cuartos y nueve octavos. Por lo que respecta a la encuadernación, hemos de suponer que la gran mayoría de estos libros se importarían sin encuadernar, al resaltar en la cuenta cuatro escasas instancias con alguna referencia rápida a su encuadernación, ya en pasta, ya en tafilete, o al hecho de que los dos tomos de uno de los títulos se encuentren encuadernados en un único volumen.

Pero el negocio, por supuesto, no terminó aquí, pues en 5 de octubre de 1762 se recibió en la Academia, por mediación de Corradi, una carta-cuenta dirigida por Boudet a Castañeda, fechada en Cádiz a 21 de septiembre, encargándole que pagase al banquero Casamayor ${ }^{76}$ siete mil quinientos noventa y cuatro reales de vellón por los siguientes efectos que había remitido por la vía de Bayonne ${ }^{77}$ :

Una esfera de Tolomeo con ruedas, en seis mil reales; un plan de París ${ }^{78}$ y un Atlas universal completo, en novecientos; un esfericogonómetro y un nivel de aire, en doscientos cincuenta; seis cañones de vidrio para el grafómetro, en veinticuatro; un libro

les iba a servir mejor para la enseñanza en su nuevo destino, o como elementos decorativos para las nuevas dependencias. En 1988, años después de convertirse la Escuela en facultad, se integró ésta en la Universidad Complutense de Madrid. Actualmente, el globo terráqueo se encuentra expuesto en la Sala de Juntas de la facultad.

76. Parece referencia al comerciante Pedro Casamayor, que en diciembre de 1782 sería nombrado uno de los primeros ocho directores del Banco de San Carlos.

77. Antoine Boudet viajó por Espańa y Portugal en 1758 -Madrid-, 1761 -Lisboa-, y 1762-63 -Cádiz-. En Madrid, en 1758, trataba de salvar de la nueva reglamentación de librería impuesta por el gobierno de Fernando VI su edición española de El gran diccionario histórico o miscelánea curiosa de la historia sagrada... traducido del francés de Luis Moreri con amplissimas adiciones y curiosas investigaciones pertenecientes a las coronas de España y Portugal... (En París, a costa de los libreros privilegiados y en Leon de Francia de los hermanos de Tournes, 1753, 10 vols., fol.). Su demanda fue denegada por el Consejo a finales de noviembre de 1759. Con fecha 10 de febrero de 1763 escribió desde Cádiz una carta a Mr. de Bombarde-que jugó algún papel en la administración de la librería en Francia-sobre el estado de la imprenta en España y Portugal, en que subraya su dependencia respecto de los libreros extranjeros, destacando el protagonismo de Lyon frente a París, y la fuerte competencia que los libreros ginebrinos, venecianos y de Aviñón hacían a los franceses (se conserva en la Biblioteca Nacional de París, Fonds français, ms. 22130/44). Vid. P. J. Guinard, art. cit.

78. Se conserva en la Biblioteca de la RABASF un ejemplar, con signatura Mp-49, del Plan de la ville et des faubourgs de Paris divisé en ses vingt quartiers par le Sr Robert de Vaugondy (París, chez l'auteur, 1760), 58,5 x 85,5 cm., dentro de una hoja de $67,5 \times 100 \mathrm{~cm}$. que incluye en sus lados izquierdo y derecho una "Table alphabétique des rues, des carrefours, des culs-de-sac, des places, des marchés, des marchés, des quais, des ports, des portes, des lieux privilégiés, des lieux remarquables, des collèges, des abbayes, des séminaires, des hôpitaux, des paroisses et des quartiers». 
de instrumentos por Bion, en sesenta. Por encajonarlo, por los derechos de la aduana de París, y gastos de la expedición, trescientos sesenta. Que todo importa los referidos siete mil quinientos noventa y cuatro reales ${ }^{79}$.

Ante la nueva e inesperada factura, sonó la alarma en la Academia, inquiriendo el secretario Hermosilla de Castańeda si había hecho esos encargos y con qué orden, a lo que contestó el teniente de arquitectura en 17 de octubre

Que no ha hecho encargo alguno a Budet; que cuando por medio de Corradi se le encargaron libros e instrumentos, para que dio una memoria, se contenía en ella la esfera armilar, pero no habiéndola enviado cuando los globos e instrumentos, a vista de lo caro de ellos y de venir muy faltos, se le cortaron todos los encargos, previniéndole remitiese las piezas que faltaban todo por medio de Corradi; que el grande Atlas de Bougundi, y el plan de París, jamás se pidieron; que las cuatro partes del mundo son partes de los globos, y están pagados con ellos; y, últimamente, que las demas piezas, o son las que faltaron a los instrumentos, o no se han pedido.

Con esto presente y tras considerar una memoria del conserje de la Academia, acompañada de sus recibos justificantes, de haber abonado la suma de quinientos cinco reales y diez maravedís de vellón por la conducción desde Bayonne y derechos de entrada de un cajón conteniendo la última remesa de Boudet, la junta particular de la Real de San Fernando acordó el 7 de noviembre

Que reteniendo la Academia los mapas y demás cosas pertenecientes a los instrumentos antes remitidos y ya pagados, se devuelvan a Budet o a quien su poder tuviere la esfera armilar y lo demás, recobrando ante todo los quinientos y cinco reales y diez maravedís que por su conducción y entrada se pagaron.

Se dio copia de esta resolución a Corradi «a fin de que la hiciese saber a Budet para su gobierno» y en diciembre de dicho año 1762 «escribió Budet a Corradi una carta llena de lamentos, declamaciones y aun injurias calificando de injusta la providencia de la Junta», carta que el librero Corradi prefirió no mostrar a la Academia. Parece ser que poco después Boudet buscó la intermediación de Felipe Samaniego ${ }^{80}$, académico de honor de San Fernando, a fin de cobrar su deuda. Tras una explicación del secretario Hermosilla con Samaniego, éste renunció a su mediación.

No se volvió a saber del asunto hasta que el librero francés remitió, con fecha 10 de febrero de 1768, un memorial a Pedro Rodríguez de Campomanes, el poderoso fiscal del Consejo de Castilla, rogándole decidiese

79. Hasta otro aviso, cito del acta de la Junta particular de 29 de julio de 1768, RABASF.

80. El arcediano Felipe García Samaniego había sido nombrado el 6 de abril de 1762 académico de honor de la Real de San Fernando, año en que tradujo la obra The Antiquities of Athens de Stuart y Revett para uso interno de la Academia. En 1764 recibió el nombramiento de académico de la Española -el año anterior, Corradi, no sabemos en qué mes, le había entregado el preceptivo juego completo del Diccionario de Autoridades, cuyo precio era entonces 570 reales. En 1765 la Academia de la Historia le acogió entre los suyos. 
cuál de los tres, la Academia, Corradi o Budet ha de sufrir la perdida de los siete mil quinientos noventa y cuatro reales de esta comisión, de que dice [Boudet] está en descubierto casi ocho años ha.

Campomanes contactó con Hermosilla, enviándole a un francés comisionado por Boudet para despachar el asunto, que le mostró entonces la correspondencia cruzada entre el librero parisino y Corradi. Pese a todo, el secretario de la Academia no cedió un ápice del acuerdo tomado, desengañando al comisionado con los documentos originales de todo el asunto. Suplicó Boudet de nuevo a la Academia que tomase resolución que le fuese más favorable y para ello, el 29 de julio de 1768

La Junta se enteró de todo, vio con mucha atención la correspondencia de Corradi y Budet. Y hallando que en todo lo alegado y declamado por éste no hay cosa que libre a su última remesa de voluntaria y maliciosa, ni que pueda ofuscar la justicia de lo resuelto en 7 de Noviembre de 62, acordó que se lleve a efecto aquella providencia en todo y por todo. Y habiendo notado en las cartas de Corradi el poco decoro y falta de verdad con que habla a Budet, quejándose de que la Academia dilataba sus pagos, y lo tenía en descubierto, sin embargo de que la Junta desprecia esta irregular, no esperada conducta, acordó que yo haga entender al mismo Corradi que está enterada de ella.

Advertencia verbal de la Academia, por boca de su secretario, al librero genovés, que tiene todo el resabio de la incomprensión fundamental entre los funcionarios ya acomodados en las instituciones del Despotismo Ilustrado y la nueva clase burguesa regida por los parámetros de lo económico. Su desencuentro, caso de que lo hubiera, ya había surtido efecto, pues Corradi, desde septiembre de 1762, no había vuelto a intervenir en la provisión de libros a la Academia de San Fernando.

La coda de todo este desacordado negocio se escuchó unos pocos años más tarde. Con fecha 6 de junio de 1774, el caballero francés Thomas Barry de Saint-Albans -posiblemente un antiguo capitán de Suizos al servicio de Espańa, nacido en Francia en una familia irlandesa- dirigió un memorial al marqués de Grimaldi, secretario del despacho de Estado, que en razón de este cargo desempeñaba también el de protector de la Academia de San Fernando:

...hace presente a Su Excelencia que, habiéndose encargado de recoger para la Real Academia de las Tres Nobles Artes de Madrid, varios libros, globos, esferas y otros instrumentos útiles para su uso, que se remitieron a ella por Mr. Boudet de París; sobre cuyo importe, habiendo acudido este interesado al Secretario de dicha Real Academia D. Ignacio de Hermosilla, examinando éste la pretensión y dado por escrito el reconocimiento de dichos efectos, le insinuó no tenía facultad para hacer su pago, sin el permiso de V.E., como director perpetuo de dicha Real Academia. En esta atención, y en la de que Mr. de Boudet, desde París, le insta sobre el pago, suplica a V.E. que, precedido el correspondiente informe de dicha Real Academia, mande satisfacer los referidos efectos. En que recibirá merced $^{81}$.

81. El memorial de T. Barry y el informe de J. de Hermosilla se encuentran en el leg. 1-24-1 de la Biblioteca de la RABASF. Téngase en cuenta que en octubre de 1774, tras un año de obras, la Academia de San Fernando se trasladó a su actual sede del palacio de Goyeneche en la calle 
Una semana más tarde, el desorientado ministro se dirigió a Hermosilla para que le informase sobre el contenido del memorial. El meticuloso y concienzudo secretario le contestó dos días más tarde, precediendo su informe con la advertencia de que "para obedecer como debo a V.E., es preciso dilatarme más de lo que quisiera. V.E., por su bondad, disimulará que por observar exactitud hable más tiempo que el que merece la materia». Tras narrar en detalle la versión que de la historia del negocio tenía la Academia, le manifiesta a Grimaldi que, de idéntico modo a como se lo cuenta,

Lo hice saber al francés interlocutor, que no sé si era D. Tomás Barry del memorial que V.E. me ha remitido y devuelvo; pero sea o no el mismo, lo cierto es que se equivoca notablemente cuando dice haber yo respondido no tenía facultad para pagar lo que figura deberse a Boudet, sin el permiso de V.E. Jamás he dado tal respuesta a él ni a otro, ni podía darla sin haber perdido el seso, estando tan clara la resolucion de la Academia, que es la mas obvia y fácil respuesta a las pretensiones de Boudet.

En suma, Señor Excelentísimo, la Junta, después de haberlas examinado dos veces, halló que Boudet envió la esfera de Tolomeo que no se le pidió después de haberle dicho con mucho tiempo que no se quería la armilar; que envió otras cosas que no se pidieron, y son inútiles; que al instante que llegaron, se previno a Boudet las recogiese; que no con la mejor fe, se desentiende en dichas instancias públicas de la resolución de la Junta habiéndola dado muy luego, como consta por su correspondencia probada; que en poder del conserje están los efectos que dice se le deben, con orden expresa de entregarlos a Boudet o a quien tenga su poder y pague primero los quinientos cinco reales y diez maravedís que por su porte y otros derechos ha desembolsado.

Esto es lo que en vista y revista, si en tales negocios pueden usarse de estas voces, está resuelto por la Academia, y lo que consta por documentos que hay en la secretaría de mi cargo y por los libros de los Acuerdos a que me refiero.

V.E. resolverá lo que sea más de su agrado.

No sabemos qué decidió el ministro, si Boudet llegó a cobrar lo que creía que la Academia le adeudaba; si recuperó el cajón con su envío y, en este caso, pagó los portes y derechos adelantados por el conserje; o si decidió en este punto dar el negocio por perdido y abandonó sus efectos. Termina aquí el rastro documental en la Academia y el único elemento que podría hacernos inclinar hacia una u otra de estas posibilidades es la presencia en la biblioteca de la Real de San Fernando de un ejemplar del Plan de la ville et des faubourgs de Paris, estampado por Robert de Vaugondy en 1760, que debió venir en la desafortunada segunda remesa de Boudet y se quedó para siempre en la institución.

Alcalá -a compartir con el Gabinete de Historia Natural-, que había sido adquirido en julio de 1773 al conde de Saceda por dos millones trescientos mil reales. 